Sexual Attitudes, Erotophobia, and Sociosexual Orientation Differ Based on Relationship Orientation

Rhonda N. Balzarinia (rbalzari@uwo.ca), Erin J. Shumlich ${ }^{\mathrm{b}}$ (eshumlic@uwo.ca), Taylor Kohut ${ }^{\mathrm{b}}$ (tkohut@uwo.ca), and Lorne Campbell (1campb23@uwo.ca)

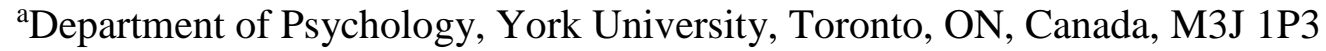

${ }^{\mathrm{b}}$ Department of Psychology, University of Western Ontario, London, ON, Canada, N6A 5C2

This research was supported by a grant awarded to Rhonda Balzarini by the Faculty of Social Sciences, University of Western Ontario

Correspondence concerning this article should be addressed to Rhonda Balzarini

Department of Psychology Main Office, Behavioural Science Building York University, Toronto, Ontario, Canada M3J 1P3

E-mail: balzarinir@gmail.com 


\begin{abstract}
Consensual non-monogamy $(\mathrm{CNM})$ is an overarching term for relationship orientations that differ based on the degree to which consensual sexual and emotional needs are fulfilled outside of a dyad. Despite the diversity of CNM relationship orientations and growing research examining CNM, it is unclear whether the sexual attitudes, inclination to approach/avoid sexual stimuli (i.e., erotophobia-erotophilia), and sociosexuality differ among individuals who identify with distinct CNM relationships. Further, as the agreements made in CNM relationships permit for extradyadic relationships, important differences might emerge for CNM and monogamous individuals. A convenience sample $(N=641)$ of individuals who self-identified as monogamous $(n=447)$, open $(n=80)$, polyamorous $(n=62)$, or swinger $(n=52)$ provided ratings of their sexual attitudes, erotophobia-erotophilia, and sociosexuality. Results indicated that swingers had the most permissive and instrumental attitudes, were the most erotophilic, and were the most unrestricted sexually. Conversely, monogamists scored the lowest on these traits. No differences emerged between relationship orientations for attitudes towards communion and birth control. These findings have important implications for sexuality research because they reinforce the view that some underlying differences and similarities exist between monogamous and CNM individuals.
\end{abstract}

Keywords: psychology and sexuality; health behaviors and attitudes; orientation; sexual minorities; quantitative/statistical survey 


\section{Sexual Attitudes, Erotophobia, and Sociosexual Orientation Differ Based on Relationship Orientation}

Consensual non-monogamy (CNM) has become increasingly visible in public and academic discourse, with more than $20 \%$ of Americans practicing some form of CNM in their lifetime (Haupert, Gesselman, Moors, Fisher, \& Garcia, 2017). CNM is an umbrella term for relationship orientations that differ based on the degree to which sexual and/or emotional needs are consensually fulfilled outside of a romantic dyad (Barker \& Langdridge, 2010). The three most common CNM relationships are swinging relationships, open relationships, and polyamory (Barker, 2011). Swinging relationships involve couples that engage in extradyadic sexual activity together, typically without emotional attachment or love for their extradyadic partners (Matsick, Conley, Ziegler, Moors, \& Rubin, 2014). Open relationships involve extradyadic sex without love and without a romantic partner's involvement in that extradyadic sex, whereas polyamorous individuals love more than one person, and often have multiple, emotionally-close relationships that may or may not include sexual involvement (Barker \& Langdridge, 2010; Matsick et al., 2014).

Given the distinctions between different forms of CNM relationships, research has examined differences in attitudes towards various CNM relationship orientations. Swingers, for example, are often perceived more negatively than people in other CNM relationships (e.g., polyamorists), possibly as the result of stigma towards their strictly sexual relationships (Matsick et al., 2014), or stigma towards promiscuity (Balzarini, Shumlich, Kohut, \& Campbell, 2018). Despite different attitudes held towards people practicing different types of CNM relationships, it is unclear if the psychosexual characteristics of individuals engaging in these different CNM relationships differ in a manner consistent with these attitudinal distinctions. What little is known 
suggests specific personality dimensions, such as openness to experience and conscientiousness, predict desire to engage in CNM (Moors, Selterman, \& Conley, 2017), while sociosexuality predicts the willingness to participate in extradyadic sex (Seal, Agostinelli \& Hannett, 1994), as well as CNM experiences (Rodrigues, Lopes, \& Smith, 2017). Relatedly, attitudes towards CNM are also more positive among people who engage in CNM than people who do not (Balzarini et al., 2018). A significant limitation of this emerging body of research is it does not differentiate between distinct CNM groups (e.g., swinging vs. open vs. polyamorous relationships). Our aim, therefore, was to examine possible differences in sexual attitudes, inclinations to approach or avoid sexual stimuli (i.e., erotophobia-erotophilia), and sociosexuality among CNM and monogamous individuals. This study advances knowledge by examining nuanced differences between monogamous, polyamorous, open, and swinger's sexual attitudes, erotophiliaerotophobia, and sociosexual orientation. This information could be useful in future hypothesis generation and could help provide insights into predicting who is likely to enter and remain in the various relationship orientations.

\section{Sexual Attitudes}

Sexual attitudes reflect a variety of values, beliefs, and orientations to sex. Sexual attitudes can be organized along four dimensions (Hendrick \& Hendrick, 1987; Hendrick, Hendrick, \& Reich, 2006): permissiveness, birth control, communion, and instrumentality. Permissiveness reflects attitudes toward casual sex. Previous research shows that people with permissive attitudes towards casual sex are more willing to engage in non-consensual extradyadic relationships (i.e., infidelity, Seal et al., 1994) and casual sexual relationships (Vrangalova \& Ong, 2014). Since swinging relationships focus on extradyadic sex rather than emotional attachment (Barker \& Langdrige, 2010), and permissiveness correlates negatively with 
commitment (Hendrick et al., 2006), we expected swingers to score higher than the other relationship orientations on permissive sexual attitudes, given that swinging is primarily defined by extra-dyadic sexual relationships. Following swingers, we expected individuals in open and polyamorous relationships would report lower but relatively high permissiveness, as these orientations permit consensual extra-dyadic sexual and emotional relationships. We further postulated that the difference between permissive sexual attitudes for those who identify as polyamorous and open might be challenging to differentiate, as previous research shows that perceptions of promiscuity among these two relationship orientations do not differ (Balzarini et al., 2018). In summary, we predicted that monogamists would be the least permissive since these relationships exclude extradyadic relationships by definition, followed by polyamorous and open relationships (with open being more or equally permissive to polyamory), and swingers being the most permissive (Hypothesis 1).

Instrumentality reflects the biological and utilitarian aspects of sex. For example, someone who is high in instrumental sexual attitudes would endorse the following statements: "Sex is primarily physical," and "The main purpose of sex is to enjoy yourself" (Hendrick et al., 2006). Research shows instrumentality correlates strongly with permissiveness and is related to disinhibition, boredom susceptibility, and sensation seeking, with the suggested link between these constructs being a restless need for pleasure without concern of rules (Hendrick \& Hendrick, 1987). These results are most consistent with swinging individuals high on sensation seeking (Houngbedji \& Guillem, 2016). Swingers tend to rate their sex lives as very satisfying and overwhelmingly (97.5\%) report swinging has made their life more exciting (Rubel \& Bogaert, 2015; Levitt, 1988). Given swinging relationships are geared towards sexual aspects of extradyadic relationships, typically without emotional attachment with the extradyadic partners 
(Matsick et al., 2014), and often involve exciting sexual experiences (Rubel \& Bogaert, 2015;

Levitt, 1988), we predicted that swingers would report the highest instrumentality scores.

Consistent with the rationale outlined for permissiveness, we expected swingers to be followed by open and polyamorous individuals (with open either greater than or equal to polyamory), and monogamous individuals to report the lowest instrumentality scores (Hypothesis 2).

We did not expect to find differences in communion or attitudes towards birth control ratings based on relationship orientation. Communion reflects the degree to which individuals endorse idealistic attitudes towards sex (e.g., "Sex is the closest form of communication between two people," and "Sex is a very important part of life," Hendrick et al., 2006). Communion positively correlates with commitment (Hendrick \& Hendrick, 1995), and while CNM relationships may consist of multiple partners, these relationship orientations still involve commitment (emotionally, sexually, or both) to one or more people. For example, polyamorous participants report higher commitment for their primary than their secondary partners, though in both cases the ratings for commitment are high and above the mid-point of the scale (see Balzarini et al., 2017), and overall, individuals in CNM relationships often report a primary partner with whom they are committed to (Cohen, 2016; Zimmerman, 2012). Therefore, we predicted that participants of all relationship orientations would similarly endorse communion beliefs (Hypothesis 3).

Attitudes towards birth control generally reflect attitudes towards sexual responsibility. For example, individuals who are high in such attitudes would endorse the following statement: "Birth control is part of responsible sexuality" (Hendrick et al., 2006). Research shows that people in CNM relationships emphasize engaging in safe sex practices, such as condom use and STI testing (Conley Moors, Ziegler, \& Karathanasis, 2012; Hutzler, Giuliano, Herselman, \& 
Johnson, 2016). Safe sex practices are also predicted to be relevant and essential in monogamous individuals' relationships, especially with women increasingly seeking pregnancy later in life (Garcia, Reiber, Massey, \& Merriwether, 2012), and some women choosing not to have children at all (Abma \& Martinez, 2006; Gillespie, 2003). Thus, engaging in safe sex practices and endorsing sexually responsible attitudes may be equally important for monogamous and CNM individuals. Therefore, we predicted that all relationship orientations would support similar attitudes towards birth control (Hypothesis 4).

\section{Erotophobia-Erotophilia}

Erotophobia-erotophilia is a sexual dimension of personality reflecting approach or avoidance orientations towards sexual stimuli (Fisher, White, Byrne, \& Kelley, 1988a). Individuals high on erotophobia have negative attitudes towards sex and sexuality (Lanciano, Soleti, Guglielmi, Mangiulli, \& Curcia, 2016). Those who are erotophobic tend to have more conservative sex roles and attitudes towards sex (Fisher et al., 1988b; Johnson, Giuliano, Herselman, \& Hutzler, 2015), experience guilt when they partake in numerous sexual activities, including masturbation and oral sex (Lanciano et al., 2016), have fewer sexual fantasies, less sexual familiarity, and are less likely to engage sex-related health care or utilize contraception (Fisher et al., 1988a; Gerrard, Kurylo, \& Reis, 1991; Lanciano et al., 2016; Rudolph, 2016). Conversely, erotophilic people report positive attitudes towards sex and sexuality (e.g., are more "sex positive," see Ivanksi, 2017). An erotophilic person is more likely to engage in diverse facets of sexuality (Lanciano et al., 2016; Rye, Serafini \& Bramberger, 2015), to think about sex more often, to masturbate and fantasize more frequently, and have more intercourse partners than erotophobic individuals (Fisher et al., 1988b). Erotophilic people are also more likely to engage 
in sex-related health care and to use contraception (Fisher et al., 1988b; Herbenick, Reece, \& Hollub, 2009; Labranche, Helweg-Larsen, Byrd, \& Choquette, 1997; Rudolph, 2016).

Therefore, it seems likely that CNM individuals would endorse more erotophilic views. As swingers often engage in extradyadic relationships without any commitment, they are likely more permissive of extradyadic sex (consistent with Hypothesis 1). Given the nature of different CNM relationships, it was predicted swingers would be the most erotophilic, followed by individuals in open relationships since those in open relationships typically engage in sexual relationships outside of the dyad. Those in polyamorous relationships were predicted to follow next due to the emphasis on committed relationships, with monogamous individuals predicted to report the least erotophilic, most erotophobic ratings (Hypothesis 5).

\section{Sociosexual Orientation}

Sociosexuality encapsulates one's behavioral tendencies and personal history with uncommitted sex, their evaluative disposition toward uncommitted sex, and desire to engage in uncommitted sex (Penke \& Asendorpf, 2008; Rodrigues et al., 2017). More sociosexually unrestricted individuals tend to pursue short-term mating strategies (e.g., higher number of sexual partners and avoidance of commitment; Jonason \& Buss, 2012; Jonason, Li, Webster, \& Schmitt, 2009), and are more likely to identify as polyamorous (Morrison, Beauliey, Brockman, \& Beaglaoich, 2013), whereas more restricted individuals adopt long-term mating strategies (Ostovich \& Sabini, 2004; Petersen \& Hyde, 2011; Simpson \& Gangestad, 1991, 1992). Individuals who are sexually unrestricted are more likely to engage in sexual activity in the absence of commitment (Simpson \& Gangestad, 1991), to report sexual infidelity (Barta \& Kiene, 2005; Ostovich \& Sabini, 2004; Seal et al., 1994; Shaw, Rhoades, Allen, Stanley, \& Markman, 2013), and engage in more flirting (Asendorpf \& Penke, 2005). However, 
sociosexually unrestricted individuals are also motivated to develop stable romantic relationships (Simpson \& Gangestad, 1991; Simpson, Wilson, \& Winterheld, 2004) and sexually invest in their bonds (Rodrigues, Lopes, \& Pereira, 2016; Tempelhof \& Allen, 2008). As such, sociosexuality is not indicative of poor relationship quality, and indeed, there is evidence that while CNM individuals are more sexually unrestricted than monogamous individuals, there are no differences between these groups in relationship satisfaction or commitment (Rodrigues et al., 2017). However, research has yet to explore differences in sociosexuality between the different types of CNM relationships, and thus it is unclear if sociosexuality differs across CNM orientations.

Given this research, it was predicted that monogamous individuals would endorse a relatively more restricted sociosexual orientation. Conversely, based on the different emphasis of various CNM relationships, it was anticipated that swingers would have the most unrestricted sociosexual orientation. Individuals in open and polyamorous relationships were predicted to follow those in swinging relationships, with open individuals predicted to have a more unrestricted or equally unrestricted sociosexual orientation as polyamorous individuals, as these individuals often form some emotional connection or commitment with extradyadic partners (Hypothesis 6).

\section{Method}

\section{Power Analysis}

To determine the optimal sample size to test our hypotheses, we conducted a power analysis for a 4-way, between-subjects, analysis of variance (ANOVA) assuming a medium effect size $(f=.25)$ with a power level of .95 (power estimated using G-Power 3.1; Erdfelder, Faul, \& Buchner, 1996; Faul, Erdfelder, Lang, \& Buchner, 2007). The power analysis indicated 
that 280 participants were needed, though we aimed to recruit a minimum of 350 participants (25\% over the $N$ indicated by our power analysis to account for incomplete data, participants who failed attention checks or did not meet inclusion criteria), and continued to collect data until there was a minimum of 50 participants per cell (see Simmons, Nelson, \& Simonsohn, 2013). This ensured that we recruited at least 50 participants for each relationship orientation.

\section{Participants and Procedure}

A convenience sample of individuals $(N=641)$ who self-identified as monogamous $(n=$ 447), open $(n=80)$, polyamorous ( $n=62)$, or swinger $(n=52)$ were recruited from Amazon's Mechanical Turk (MTurk) website, an online crowdsourcing platform that is commonly used for psychological research. Four advertisements (for individuals who self-identified as either monogamous, open, swinging, or polyamorous) were placed on the MTurk website for all MTurk users with active accounts in the United States to see. The advertisement contained information about the inclusion criteria (e.g., speak and read English fluently, at least 18 years old, have a 97\% approval rating on MTurk, and identify as either monogamous, swinger, open, or polyamorous) as well as a link to the survey. Participants were primarily white (65.8\%), heterosexual (84.6\%), males (58.3\%), who were married (38.2\%) or dating (38.5\%) their partners and were in their early 30 's $(M=32.1, S D=9.5)$. Demographic information for the participants broken down by relationship orientation are presented in Table 1.

Eligible and interested participants followed the link that redirected them to a survey hosted on Qualtrics, where the letter of information and consent was presented. Within the letter of consent, participants were told that the purpose of this study was to better understand sociosexual orientation (SOI) and attitudes towards sex. Informed consent was received from each participant digitally, and each participant indicated they read the consent form and agreed to 
take part before proceeding. After consenting, participants completed a short questionnaire that assessed demographic information, followed by questionnaires that assessed their sexual attitudes, erotophobia-erotophilia, and sociosexual orientation. Once surveyss were complete, participants were provided debriefing information (i.e., further details about the study's hypotheses) along with a code which could be used to claim their compensation for taking part in the study (to view the materials for recruitment, co and consent, please see https://osf.io/vmp59/). The hypotheses concerning sexual attitudes, the tendency to approach or avoid sexual stimuli, and sociosexual orientation among different relationships orientations were preregistered before conducting analyses though after data was collected (see: https://osf.io/sy94j/), and all study materials are available through the Open Science Framework (see: https://osf.io/4mxy3/).

\section{Measures}

Relationship Orientation. Relationship orientation was verified in two ways. First, participants selected into the survey from one of four advertisements that were directed to either monogamous, polyamorous, open, or swingers. Second, participants were asked to identify their current relationship orientation (e.g., "What best characterizes your current relationship orientation?") and were provided the following options: monogamous, polyamorous, open, swinger, or other. Participants who indicated that they identified with another orientation were excluded from analyses.

Sexual Attitudes. The Brief Sexual Attitudes Scale (BSAS; Hendrick et al., 2006) was used to assess attitudes towards permissiveness, instrumentality, birth control, and communion. Participants were asked to indicate the extent they agreed or disagreed with a series of statements for each subscale. Items were divided into four components: permissiveness (ten items; $\alpha=.93$; 
e.g., "I do not need to be committed to a person to have sex with him/her"), instrumentality (five items; $\alpha=.81$; e.g., "The main purpose of sex is to enjoy oneself"), communion (five items; $\alpha=$ .88 ; e.g., "Sex is the closest form of communication between two people"), and birth control (three items; $\alpha=.92$; e.g., "Birth control is part of responsible sexuality"). Participants responded using a 5-point Likert-like scale ranging from 1 ("strongly agree") to 5 ("strongly disagree"). Items for each subscale were reverse scored and mean averaged to create scores that ranged from low to high endorsement for each attitude. The BSAS has demonstrated good reliability and validity (e.g., Hendrick et al., 2006).

Erotophobia-Erotophilia. The Sexual Opinion Survey (SOS; Fisher et al., 1988b) was used to assess erotophobia-erotophilia. Participants were asked to indicate the extent they agreed or disagreed with 21 statements such as, "Almost all erotic (sexually explicit) material is nauseating" and "If people thought I was interested in oral sex, I would be embarrassed" ( $\alpha=$ .87). Participants responded using a 7-point Likert-like scale ranging from strongly agree to strongly disagree. This was scored according to the original author's criteria (see Fisher et al., 1988b, for scoring instructions), with scores ranging from 0 (most erotophobic) to 126 (most erotophilic). This scale has been found to be a good predictor of total SOS scores for both women and men (Fisher et al., 1998b). The SOS has shown good test-retest reliability as well as construct and discriminant validity.

Sociosexual Orientation. The Revised Sociosexual Orientation Inventory (SOI-R; Penke \& Asendorpf, 2008) was used to assess willingness to engage in uncommitted sexual encounters. Items are divided into three components: behavior (three items; $\alpha=.82$; e.g., "With how many different partners have you had sex within the past 12 months?"), attitudes (three items; $\alpha=.81$; e.g., "Sex without love is okay"), and desire (three items; $\alpha=.91$; e.g., "How often do you have 
fantasies about having sex with someone with whom you do not have a committed romantic relationship?"). The responses were mean aggregated to create a total score $(\alpha=.88)$, where higher mean scores on each component signify more unrestricted behaviors, attitudes, and desires (i.e., unrestricted sociosexual orientation). The SOI-R has demonstrated good reliability and validity (e.g., Penke \& Asendorpf, 2008).

\section{Data Analytic Strategy}

To assess how attitudes and behaviors differ among various relationship configurations, we conducted a between-subject (self-identified relationship orientation: monogamous vs. polyamorous vs. open relationship vs. swinging relationship) analysis of variance (ANOVA) for each of the outcome measures: BSAS, SOS, SOI-R. These analyses were conducted using a Bonferroni correction. The effect size, or eta squared $\left(\eta_{p}^{2}\right)$, is presented with the results for each ANOVA. The effect sizes can be interpreted based on Cohen's (1988) guidelines, which suggests 0.01 is a small effect, 0.059 is a medium effect, while 0.138 or above is a large effect. Furthermore, we sought to assess whether the CNM subtypes differed with regards to various demographics (e.g., age, gender, sexual orientation, race, religion, political affiliation) and conducted analyses of covariance (ANCOVAs) controlling for demographic differences when they emerged (specifically with gender, sexual orientation, race, and religious affiliation).

\section{Results}

\section{Preliminary Data}

Pearson's zero-order correlations were calculated. The permissiveness ratings were positively correlated with instrumentality, communion, birth control, erotophobia-erotophilia, and sociosexuality. Instrumentality ratings were positively associated with communion, birth control, erotophobia-erotophilia, and sociosexuality. The communion ratings correlated with 
birth control, erotophobia-erotophilia, though did not correlate with sociosexuality. The birth control ratings positively correlated with erotophobia-erotophilia, and sociosexuality. Lastly, a positive correlation between erotophobia-erotophilia and sociosexuality emerged. Table 2 presents the overall correlations and the correlations for each variable broken down by relationship orientation.

In most cases, results among each relationship orientation (e.g., among those who identify as monogamous, polyamorous, etc.) were consistent with the overall results discussed above. However, interestingly, monogamous individuals' ratings for permissiveness were not correlated with communion, though these variables were positively correlated for all CNM orientations. In fact, in follow-up analyses comparing correlation coefficients for those who identified as monogamous and each CNM subtype indicated that the magnitude of these correlations differed significantly between monogamous people and people from each CNM subtype (all $p<.001)$.

\section{Confirmation of Assumptions of Normality}

The distribution of the residuals for each analysis was assessed to confirm assumptions of normality. The skewness and kurtosis of all residuals were examined - following West and colleagues (1995) guidelines, wherein a skewness of \pm 2 , and kurtosis of \pm 7 are deemed acceptable. In all instances, the skewness and kurtosis fell below these standards and thus the assumption of normality was met, and analyses are presented without any corrections.

\section{Primary Findings}

Sexual Attitudes. Consistent with the hypothesis that sexual attitudes would differ based on relationship orientation, with monogamists reporting the least permissive attitudes and swingers reporting the most (Hypothesis 1), there was a significant main effect of the 
participants' relationship orientation on reported permissiveness, $F(3,626)=41.50, p<.001, \eta_{p}{ }^{2}$ $=.17$. Based on Cohen's (1988) standards for interpreting $\eta_{p}{ }^{2}$, this effect would be considered large. Permissiveness was lowest among monogamous individuals and highest among swingers, with open and polyamorous individuals in the middle. Monogamists' permissiveness ratings were significantly different from those provided by participants in polyamorous, open, and swinging relationships (all $p<.001$ ). There was also a significant difference between individuals who identified as open and swingers on permissiveness ratings. The differences in ratings between individuals in other CNM orientations were not significantly different from one another (see Tables 3- and 4). Importantly, effects remained significant when controlling for gender, sexual orientation, race, and religious affiliation, $F(3,625)=35.74, p<.001, \eta_{p}^{2}=.15$.

Similarly, we expected that those who identify as monogamous would report the lowest instrumentality, while those who identify as swingers would endorse the most instrumentality (Hypothesis 2). Consistent with this hypothesis, there was a significant main effect of the participants' relationship orientation on reported instrumentality, $F(3,626)=13.74, p<.001, \eta_{p}{ }^{2}$ $=.06$. The effect size for differences in instrumentality was moderate, and instrumentality was lowest for monogamous individuals and greatest for swingers. The instrumentality rating for monogamists was significantly different from individuals who identified as polyamorous, open, and swingers. Among those who identified as CNM, there was a significant difference between polyamorists and swingers. Differences in ratings among other CNM orientations were nonsignificant (see Table 3 and 4). Effects for instrumentality remained significant when controlling for gender, sexual orientation, race, and religious affiliation, $F(3,625)=13.51, p<.001, \eta_{p}^{2}=$ .06 . 
Unlike permissiveness and instrumentality, null effects for relationship orientation were predicted for communion (Hypothesis 3) and attitudes towards birth control (Hypothesis 4). Consistent with the predictions, there was not a significant main effect of the participants' relationship orientation on reported communion, $F(3,626)=1.39, p=.244, \eta_{p}^{2}=.01$, and birth control, $F(3,626)=1.58, p=.193, \eta_{p}{ }^{2}=.01$, and these effects remained non-significant when we controlled for demographic differences.

Erotophilia-Erotophobia. We expected one's propensity to approach or avoid sexual stimulus to differ by relationship orientation (Hypothesis 5), such that those who identify as monogamous would be the most erotophobic while those who identify as swingers would be the most erotophilic. Consistent with this hypothesis, a significant main effect emerged in the analysis assessing erotophobia-erotophilia scores, $F(3,623)=8.66, p<.001, \eta_{p}^{2}=.04$. Monogamous individuals were the most erotophobic and swingers were the least erotophobic/most erotophilic, though the effect size for these differences was small. Post-hoc tests revealed that the erotophobia ratings for monogamists were significantly different from polyamorists, and swingers, though did not differ from individuals in open relationships. The differences in ratings between individuals in open, swinging, and polyamorous relationships were not significant (see Table 3 and 4). Importantly, effects remained significant when controlling for gender, sexual orientation, race, and religious affiliation, $F(3,622)=7.33, p<$ $.001, \eta_{p}^{2}=.04$.

Sociosexual Orientation. Lastly, we expected sociosexual orientation to differ based on relationship orientation, such that monogamous individuals would report the most restricted sociosexuality while swingers would report the most unrestricted sociosexuality (Hypothesis 6). Consistent with this prediction, there was a significant main effect of the participants' 
relationship orientation on their sociosexual orientation, $F(3,630)=50.27, p<.001, \eta_{p}{ }^{2}=.19$, and the effect size for this finding was large. Descriptive statistics revealed that monogamous individuals were the most sexually restricted and swingers were the most sexually unrestricted, with individuals who identified as open and polyamorous in the middle. Furthermore, the sociosexuality ratings for monogamists was significantly different from individuals who identified as polyamorous, and swingers, though the differences in ratings between open, swinging, and polyamorous individuals were not significantly different from one another (see Table 3 and 4). Importantly, effects remained significant when controlling for gender, sexual orientation, race, and religious affiliation, $F(3,629)=44.96, p<.001, \eta_{p}{ }^{2}=.18 .{ }^{1}$

\section{Discussion}

The goals of the current research were to understand how sexual attitudes, one's inclination to approach or avoid sexual stimuli (i.e., erotophobia-erotophilia), and sociosexuality differ among individuals based on their relationship orientation. The current research suggests that individuals in CNM and monogamous relationships have differing sexual attitudes, erotophobia-erotophilia, and sociosexuality. Regarding sexual attitudes, results show monogamists endorsed the least permissive and instrumental attitudes towards sex, whereas individuals in swinging relationships endorsed the most permissive and instrumental attitudes. There were no differences between relationship orientations for communion and birth control, as predicted. In terms of erotophobia-erotophilia, monogamists were most erotophobic, while swingers were the most erotophilic. Lastly, the results suggest that monogamous individuals were the most sexually restricted, whereas individuals in CNM relationships endorsed more

\footnotetext{
${ }^{1}$ As individuals can consider themselves to be monogamous, polyamorous, etc., regardless of their current relationship status (e.g., when single), we include individuals who are single as well as in a relationship in our analyses. However, the results reported held when we assessed effects among those who were currently in relationship excluding single participants, and vice versa.
} 
unrestricted sexuality. Across the findings, the effect sizes ranged from small to large, with the smallest effect size emerging for differences in erotophobia-erotophilia, and the largest effect emerging among differences in sociosexuality. Furthermore, all effects remained when controlling for gender, sexual orientation, race, and religious affiliation.

Despite general support for the predictions, the differences among those in CNM orientations (especially among open and polyamorous participations) were surprisingly small, with only a few significant differences in dependent measure ratings. The hypotheses for the current study were premised on the assumption that the subtypes of CNM orientations differ in the extent to which partners value love and emotional involvement to be a part of their multiple relationships, such that some relationship orientations emphasize loving more than one person (i.e., polyamory), while others emphasize having sex without love (i.e., swinging), or involve having sex without love without a partner's participation (i.e., open relationships) (Matsick et al., 2014). Previous research also suggests there are normative boundaries and different levels of stigma directed towards specific CNM relationship orientations (Frank \& DeLameter, 2010; Balzarini et al., 2018), such that polyamory is evaluated more positively than purely pleasurefocused relationship orientations, such as swinging. Given the definitional differences among the different subtypes of CNM and considering the documented antipathy these group express for each other, we expected larger differences to exist between the CNM orientations than the current results show.

There are a few explanations for the lack of differences between CNM groups. It is possible the measures included were not sensitive enough to the variation between CNM relationship orientations since these measures were validated on monogamous samples. For example, items from the sociosexuality measure (SOI-R) presume that sex without love, 
fantasies of uncommitted sex, and the raw number of sexual partners in a year are representative of unrestricted sexuality. However, all of these SOI-R items may be more likely among CNM relationships. As such, this scale may not be representative of what unrestricted sexuality might look like among various CNM relationships.

Another potential explanation for the lack of differences between CNM groups may be reflective of actual similarities between individuals in these relationship orientations. Previous research looking at these groups are based on perceptions of these groups, rather than real differences (Balzarini et al., 2018; Conley, Moors, Matsick, \& Ziegler, 2013; Moors, Matsick, Ziegler, Rubin, \& Conley, 2013), and there may be more similarities than suggested by research which has shown differences in perceptions of and stigma towards the most common CNM relationship orientations. Further, the definitions of CNM relationship orientations may not necessarily reflect actual differences among those in CNM relationships; instead they may be premised on perceptions and beliefs. A further complication is that individuals in CNM relationships may not necessarily identify with a specific relationship orientation because there is likely a degree of fluidity across these categories. Specifically, individuals may switch between relationship orientations (Manley, Diamond, \& van Anders, 2015), or have relationships that do not necessarily fit within a specific category (e.g., someone who identifies as polyamorous may be in a relationship that more closely resembles an open relationship).

Lastly, the lack of significant differences may be due to relatively low statistical power in our CNM participant groups. While we ensured that we had at least 50 participants per relationship orientation, we had substantially fewer CNM participants then we did monogamous participants. The sensitivity of the analyses comparing the CNM subgroups is therefore relatively low. In this connection, it may also be that differences between the CNM subgroups are smaller 
than the differences between monogamous and CNM groups overall, requiring larger sample sizes within those groups.

Additional novel findings in this study, and in line with our predictions, are that communion and birth control ratings did not differ between relationship orientations. These findings may counter expectations that CNM participants endorse less idealistic attitudes towards sex (Conley et al., 2013) or have less positive attitudes towards safe sex compared to monogamists (as individuals who practice CNM are perceived to be more likely to spread STIs; Johnson et al., 2015). However, these results are in line with previous research that shows that individuals who engage in CNM relationships report high levels of commitment, intimacy, and satisfaction in their relationships (Balzarini et al., 2017; Bonello \& Cross, 2010; Conley, Matsick, Moors, \& Ziegler, 2017; Ritchie \& Barker, 2006), and engage in sex safe sex (Conley et al., 2012; Hutzler et al., 2016).

Another noteworthy finding involves the correlations among the scales. Interestingly, there were some correlations between these scales that emerged for non-monogamists though did not for monogamists or were weaker among monogamous individuals (see Table 2). For example, permissiveness and communion (i.e., idealistic attitudes towards sex) were not correlated for monogamists but were strongly correlated for all other CNM orientations. Previous research has reported small correlations for these variables (Hendrick et al., 2006), but has suggested these findings were not conceptually significant. We posit these findings could be meaningful, especially in the context of including subtypes of CNM, such that for monogamous individuals, extradyadic relationships are antithetical to their relationship agreements. Conversely, the ability to experience communion and permissiveness simultaneously may be more consistent with the agreements made in CNM relationships, such that one can experience 
sex with love in one relationship, for example in the primary relationship, and yet pursue extradyadic relationships with varying levels of commitment (or no commitment). Similarly, while the correlation for instrumentality and communion was significant, though small, for monogamous participants, it was significantly stronger among individuals CNM relationships. In previous research with monogamous participants (Hendrick \& Hendrick, 1987; Hendrick et al., 2006), the relationship between instrumentality and communion was not significant.

The findings from this study could be useful in future hypothesis generation. For example, one promising direction to explore is whether differences in sexual attitudes and opinions influence stigma. Previous research has shown that individuals in CNM relationships experience robust stigma (Conley et al., 2013; Moors, Matsick, Ziegler, Rubin, \& Conley, 2013), though among CNM targets polyamorous individuals are the least stigmatized and swingers are the most (Balzarini et al., 2018; Matsick et al., 2014). Some research suggests that sexual promiscuity may contribute to this effect (Matsick et al., 2014), and other research suggests that perceptions of STIs but not promiscuity contributed to stigma towards CNM orientations (Balzarini et al., 2018), with open, polyamorous, and monogamous individuals perceiving swingers to be the most likely to have an STI. As such, it is possible that stigma towards swingers also stems from their differing sexual attitudes, inclination to approach or avoid sexual stimuli, and sociosexuality. Furthermore, if individuals can accurately perceive these qualities, as previous research on sociosexuality suggests (see Stillman \& Maner, 2008, which shows that sociosexuality can be detected by strangers based on brief observations of behavior), then it is possible that such views influence perceptions of STI risk which could then influence stigma. Additionally, this research could help provide insights into predicting who is likely to enter and remain in the various relationship orientations. More specifically, it is possible that 
individuals with various orientations seek out relationships that are consistent with their sexual attitudes, inclination to approach or avoid sexual stimuli, and sociosexuality. For example, it would make sense that individuals who have conservative sexual attitudes, express aversions to sexual stimuli, and are typically restricted sexually would prefer a monogamous relationship orientation. Conversely, those who express liberal sexual attitudes, tend to seek out sexual stimulus, and are unrestricted sexually should prefer a non-monogamous relationship. In addition, because similarity regarding opinions, personality traits, values, and interests is one of the strongest determinants of interpersonal attraction (Alves, 2018; Byrne, 1961, 1971; Byrne, Griffit, \& Stefaniak, 1967; Montoya, Horton, \& Kirchner, 2008) and couples' sexual attitude similarity predicts satisfaction and commitment (Cupach \& Metts, 1995), individuals may be more attracted to and satisfied with partners who report similar sexual attitudes, inclination to approach sexual stimulus, sociosexuality, and relationship orientation.

Lastly, this research could have important clinical implications. In addition to pervasive discrimination of CNM individuals (Conley et al., 2013), individuals may experience higher levels of discrimination the further away they are from the "in-group" (i.e., monogamy) (Bettencourt, Charlton, Borr, \& Hume, 2001). Non-monogamous individuals who deviate most from monogamy (i.e., have a higher number of relationships, are more apt to seek out sexual stimuli, and are sexually unrestricted) experience more discrimination, harassment, and violence (Witherspoon, 2016). The substantial differences between monogamy and swingers suggest that swingers may be particularly vulnerable to pervasive stigma, discrimination, harassment, violence, and judgment, including from health care professionals (Jordon, 2018), which is in line with previous research documenting greater stigma towards swingers than polyamorists or individuals in open relationships. Furthermore, some of the most commonly used scales and 
assessment tools in research and clinical work were developed from a monogamous framework (Girard \& Brownlee, 2015); therefore, CNM individuals may not be adequately represented or treated accordingly within the health care system. The current research provides a greater understanding of the nuances between CNM relationships that could inform ongoing efforts to advise mental health care professionals of relationship orientations outside of monogamy (e.g., Girard \& Brownlee, 2015). For example, it has been advised that mental health care professionals should validate CNM clients' experiences and identity (Moors \& Schechinger, 2014), which may also include validating individuals' sociosexuality, and sexual attitudes, beliefs, and behaviors.

\section{Limitations and Directions for Future Research}

The current research has some limitations that may impact the interpretability of our findings. First, our data were cross-sectional and did not allow for causal inferences. It is possible that one's decision to identify with and pursue a subtype of CNM is influenced by sexual attitudes, erotophilia-erotophobia, and sociosexuality, or, conversely, that one's relationship orientation has influences on their sexual attitudes, erotophilia-erotophobia, and sociosexuality. This limitation could be addressed through longitudinal research examining sexual attitudes, erotophilia-erotophobia, and sociosexuality over time. Second, results may be influenced by participants' self-selection to participate in a study about sex; therefore, there may be self-selection for individuals who are more comfortable and have an approach orientation to sexual stimuli (Saunders, Fisher, Hewitt, \& Clayton, 1985) than those who would reject participation. Future research should seek to replicate these findings with a more generalizable sample.

\section{Concluding Remarks}


A non-trivial number of individuals engage in CNM relationships, yet researchers are just beginning to understand what might motivate individuals to seek out CNM relationships. This research is among the first to examine whether sexual attitudes, the inclination to approach or avoid sexual stimuli (i.e., erotophobia-erotophilia), and sociosexuality differ among individuals who self-identify as monogamy, polyamorous, open, or swinger. As such, results suggest an individual's sexual attitudes, erotophobia, and sociosexuality vary based on their relationship orientation. These qualities may influence individual's decision to seek out consensually nonmonogamous arrangements (e.g., individuals who are erotophilic and sexually unrestricted may be more apt to seek out CNM), and consequently, may be more indicative of low satisfaction in monogamous relationships than CNM relationships. Furthermore, as previous research has shown that individuals in CNM relationship are stigmatized, it is possible that perceptions of high permissiveness, instrumentality, erotophilia, and sociosexuality influences stigma (e.g., if a monogamous individual perceives swingers to be sexually unrestricted and to have permissive sexual attitudes, do they then stigmatize swingers more?). As such, the implications of these differences and similarities in sexual attitudes, erotophobia-erotophilia, and sociosexuality warrant further exploration. 


\section{References}

Abma, J. C., \& Martinez, G. M. (2006). Childlessness among older women in the United States: Trends and profiles. Journal of Marriage and Family, 68, 1045-1056.

Alves, H. (2018). Sharing rare attitudes attracts. Personality and Social Psychology, 44, 12701283.

Asendorpf, J. B., \& Penke, L. (2005). A mature evolutionary psychology demands careful conclusions about sex differences. Behavioral and Brain Sciences, 28, 275-276.

Balzarini, R. N., Campbell, L., Kohut, T., Holmes, B. M., Lehmiller, J. J., Harman, J. J., \& Atkins, N. (2017). Perceptions of primary and secondary relationships in polyamory. PLOS ONE, 12, 1-20.

Balzarini, R. N., Shumlich, E., Kohut, T., \& Campbell, L. (2018). Dimming the "halo" around Monogamy: Re-assessing stigma surrounding consensually non-monogamous romantic relationships as a function of personal relationship orientation. Frontiers in Psychology, $9,1-12$.

Barta, W. D., \& Kiene, S. M. (2005). Motivations for infidelity in heterosexual dating couples: The roles of gender, personality differences, and sociosexual orientation. Journal of Social and Personal Relationships, 22, 339-360.

Barker, M. (2011). Monogamies and non-monogamies: A response to 'The challenge of monogamy: Bringing it out of the closet and into the treatment room' by Marianne Brandon. Sexual and Relationship Therapy, 26, 281-287.

Barker, M., \& Langdridge, D. (2010). Whatever happened to non-monogamies? Critical reflections on recent research and theory. Sexualities, 13, 748-772. 
Bettencourt, B., Charlton, K., Dorr, N., \& Hume, D. L. (2001). Status differences and in-group bias: A meta-analytic examination of the effects of status stability, status legitimacy, and group permeability. Psychological Bulletin, 127, 520-542.

Bonello, K., \& Cross, M. C. (2010). Gay monogamy: I love you but I can't have sex with only you. Journal of Homosexuality, 57, 117-139.

Byrne, D. (1961). Interpersonal attraction and attitude similarity. The Journal of Abnormal and Social Psychology, 62, 713-715.

Byrne, D. (1971). The attraction paradigm. New York, NY: Academic Press.

Byrne, D., Griffitt, W., \& Stefaniak, D. (1967). Attraction and similarity of personality characteristics. Journal of Personality and Social Psychology,5, 82-90.

Cohen, M. T. (2016). An exploratory study of individuals in non-traditional, alternative relationships: How "open" are we? Sexuality and Culture, 20, 295-315.

Cohen, J. (1988). Statistical power analysis for the behavioral sciences (2nd ed.). Hillsdale, NJ: Lawrence Erlbaum Associates.

Conley, T. D., Matsick., J., Moors., A. C., \& Ziegler, A. (2017). Investigation of consensually nonmonogamous relationships: Theories, methods, and new directions. Perspectives on Psychological Science, 12, 205-232.

Conley, T. D., Moors, A. C., Matsick, J. L., \& Ziegler, A. (2013). The fewer the merrier?: Assessing stigma surrounding consensually non-monogamous romantic relationships. Analyses of Social Issues and Public Policy, 13, 1-30.

Conley, T. D., Moors, A. C., Ziegler, A., \& Karathanasis, C. (2012). Unfaithful individuals are less likely to practice safer sex than openly nonmonogamous individuals. The Journal of Sexual Medicine, 9, 1559-1565. 
Cupach, W. R., \& Metts, S. (1995). The role of sexual attitude similarity in romantic heterosexual relationships. Personal Relationships, 2, 287-300.Erdfelder, E., Faul, F., \& Buchner, A. (1996). GPOWER: A general power analysis program. Behavior Research Methods, Instruments, \& Computers, 28, 1-11.

Faul, F., Erdfelder, E., Buchner, A., \& Lang, A. G. (2009). Statistical power analyses using G* Power 3.1: Tests for correlation and regression analyses. Behavior Research Methods, 41, $1149-1160$.

Fisher, W. A., White, L. A., Byrne, D., \& Kelley, K. (1988a). Erotophobia-erotophilia as a dimension of personality. Journal of Sex Research, 25, 123-151.

Fisher, W. A., Grenier, G., Watters, W. W., Lamont, J., Cohen, M., \& Askwith, J. (1988b). Students' sexual knowledge, attitudes toward sex, \& willingness to treat sexual concerns. Academic Medicine, 63, 379-385.

Frank, K., \& DeLamater, J. (2010). Deconstructing monogamy: Boundaries, identities, and fluidities across relationships. In M. Barker and D. Langdridge (Eds.), Understanding non-monogamies (pp. 9-22). New York, NY: Routledge.

Garcia, J. R., Reiber, C., Massey, S. G., \& Merriwether, A. M. (2012). Sexual hookup culture: A review. Review of General Psychology, 16, 161-176.

Gerrard, M., Kurylo, M., \& Reis, T. (1991). Self-esteem, erotophobia, and retention of contraceptive information in the classroom. Journal of Applied Social Psychology, 21, $368-379$.

Gillespie, R. (2003). Childfree and feminine: Understanding the gender identity of voluntarily childless women. Gender and Society, 17, 122-136. 
Girard, A., \& Brownlee, A. (2015). Assessment guidelines and clinical implications for therapists working with couples in sexually open marriages. Sexual and Relationship Therapy, 30, 462-474.

Haupert, M., Gesselman, A., Moors, A., Fisher, H., \& Garcia, J. (2017). Prevalence of experiences with consensual non-monogamous relationships: Findings from two nationally representative samples of single Americans. Journal of Sex and Marital Therapy, 43, 424-440.

Hendrick, S. S., \& Hendrick, C. (1987). Multidimensionality of sexual attitudes. Journal of Sex Research, 23, 502-526.

Hendrick, S. S., \& Hendrick, C. (1995). Gender differences and similarities in sex and love. Personal Relationships, 2, 55-65.

Hendrick, C., Hendrick, S. S., \& Reich, D. A. (2006). The brief sexual attitudes scale. Journal of Sex Research, 43, 76-86.

Herbenick, D., Reece, M., \& Hollub, A. (2009). Inside the ordering room: Characteristics of women's in-home sex toy parties, facilitators and sexual communication. Sexual Health, 6, 318-327.

Houngbedji, A., \& Guillem, E. (2016). Profiles and sexual practices of current and past swingers interviewed on French websites. Sexologies, 25, 1-4.

Hutzler, K. T., Giuliano, T. A., Herselman, J. R., \& Johnson, S. M. (2016). Three's a crowd: Public awareness and (mis)perceptions of polyamory. Psychology and Sexuality, 7, 6987.

Ivanski, C. (2017). Sexual Attitudes Sale development (honour's thesis). Western University, London, Canada. 
Johnson, S. M., Giuliano, T. A., Herselman, J. R., \& Hutzler, K. T. (2015). Development of a brief measure of attitudes towards polyamory. Psychology \& Sexuality, 6, 325-339.

Jonason, P. K., \& Buss, D. M. (2012). Avoiding entangling commitments: Tactics for implementing a short-term mating strategy. Personality and Individual Differences, 52, 606-610.

Jonason, P. K., Li, N. P., Webster, G. W., \& Schmitt, D. P. (2009). The Dark Triad: Facilitating short-term mating in men. European Journal of Personality, 23, 5-18.

Jordan, L. S. (2018). "My mind kept creeping back... this relationship can't last": Developing self-awareness of monogamous bias. Journal of Feminist Family Therapy, 30, 109-127.

Labranche, E. R., Helweg-Larsen, M., Byrd, C. E., \& Choquette, R. A. (1997). To picture or not to picture: Levels of erotophobia and breast self-examination brochure techniques. Journal of Applied Social Psychology, 27, 2200-2212.

Lanciano, T., Soleti, E., Guglielmi, F., Mangiulli, I., \& Curci, A. (2016). Fifty shades of unsaid: Women's explicit and implicit attitudes towards sexual morality. European Journal of Psychology, 12, 550-566.

Levitt, E. E. (1988). Alternative life style and marital satisfaction: A brief report. Analysis of Sex Research, 1, 455-461.

Manley, M. H., Diamond, L. M., \& van Anders, S. M. (2015). Polyamory, monogamy, and sexual fluidity: A longitudinal study of identity and sexual trajectories. Psychology of Sexual Orientation and Gender Diversity, 2, 168-180.

Matsick, J. L., Conley, T. D., Ziegler, A., Moors, A. C., \& Rubin, J. D. (2014). Love and sex: Polyamorous relationships are perceived more favourably than swinging and open relationships. Psychology \& Sexuality, 5, 339-348. 
Montoya, R. M., Horton, R. S., \& Kirchner, J. (2008). Is actual similarity necessary for attraction? A meta-analysis of actual and perceived similarity. Journal of Social and Personal Relationships, 25, 889-922.

Moors, A. C., \& Schechinger, H. (2014). Understanding sexuality: Implications of Rubin for relationship research and clinical practice. Sexual and Relationship Therapy, 29, 476482.

Moors, A. C., Matsick, J. L., Ziegler, A., Rubin, J. \& Conley, T. D. (2013). Stigma toward individuals engaged in consensual non-monogamy: Robust and worthy of additional research. Analyses of Social Issues and Public Policy, 13, 52-69.

Moors, A. C., Selterman, D., \& Conley, T. D. (2017). Personality correlates of desire to engage in consensual non-monogamy among lesbian, gay, and bisexual individuals. Journal of Bisexuality, 4, 418-434.

Morrison, T. G., Beaulieu, D., Brockman, M., \& Beaglaoich, C. Ó. (2013). A comparison of polyamorous and monoamorous persons: Are there differences in indices of relationship well-being and sociosexuality? Psychology \& Sexuality, 4, 75-91.

Ostovich, J. M., \& Sabini, J. (2004). How are sociosexuality, sex drive, and lifetime number of sexual partners related? Personality and Social Psychology Bulletin, 30, 1255-1266.

Penke, L., \& Asendorpf, J. B. (2008). Beyond global sociosexual orientations: A more differentiated look at sociosexuality and its effects on courtship and romantic relationships. Journal of Personality and Social Psychology, 95, 1113-1135.

Petersen, J. L., \& Hyde, J. S. (2011). Gender differences in sexual attitudes and behaviors: A review of meta-analytic results and large datasets. Journal of Sex Research, 48, 149-165. 
Ritchie, A., \& Barker, M. (2006). ‘There aren't words for what we do or how we feel so we have to make them up': Constructing polyamorous languages in a culture of compulsory monogamy. Sexualities, 9, 584-601.

Rodrigues, D., Lopes, D., \& Pereira, M. (2016). "We agree and now everything goes my way": Consensual sexual nonmonogamy, extradyadic sex, and relationship satisfaction. Cyberpsychology, Behavior, and Social Networking, 19, 373-379.

Rodrigues, D., Lopes, D., \& Smith, C. V. (2017). Caught in a "bad romance"? Reconsidering the negative association between sociosexuality and relationship functioning. Journal of Sex Research, 54, 1118-1127.

Rubel, A. N., \& Bogaert, A. F. (2015). Consensual nonmonogamy: Psychological well-being and relationship quality correlates. Journal of Sex Research, 52, 1-22.

Rudolph, K. (2016). Sexual risk behaviors in college women: Perceived norms, attitudes, and sexual motives (Unpublished masters thesis). East Carolina University, Greenville, NC.

Rye, B. J., Serafini, T., \& Bramberger, T. (2015). Erotophobic or erotophilic: What are young women's attitudes towards BDSM? Psychology and Sexuality, 6, 340-356.

Saunders, D. M., Fisher, W. A., Hewitt, E. C., \& Clayton, J. P. (1985). A method for empirically assessing volunteer selection effects: Recruitment procedures and responses to erotica. Journal of Personality and Social Psychology, 49, 1703-1712.

Seal, D. W., Agostinelli, G., \& Hannett, C. A. (1994). Extradyadic involvement: Moderating effects of sociosexuality and gender. Sex Roles, 31, 1-22.

Shaw, A. M., Rhoades, G. K., Allen, E. S., Stanley, S. M., \& Markman, H. J. (2013). Predictors of extradyadic sexual involvement in unmarried opposite-sex relationships. Journal of Sex Research, 50, 598-610. 
Simmons, J. P., Nelson, L. D., \& Simonsohn, U. (2013). Life after p-hacking. Meeting Society of Personality Social Psychology, New Orleans, LA. Retrieved from http://ssrn.com/abstract=2205186.Simpson, J. A., \& Gangestad, S. W. (1991). Individual differences in sociosexuality: Evidence for convergent and discriminant validity. Journal of Personality and Social Psychology, 60, 870-883.

Simpson, J. A., \& Gangestad, S. W. (1992). Sociosexuality and romantic partner choice. Journal of Personality, 60, 31-51.

Simpson, J., Wilson, C., \& Winterheld, H. (2004). Sociosexuality and romantic relationships. In J. H. Harvey, A. Wenzel, \& S. Sprecher (Eds.), The handbook of sexuality in close relationships (pp. 87-112). Mahwah, NJ: Erlbaum.

Tempelhof, T., \& Allen, J. (2008). Partner-specific investment strategies: Similarities and differences in couples and associations with sociosexual orientation and attachment dimensions. Personality and Individual Differences, 45, 41-48.

Stillman, T. F., \& Maner, J. K. (2009). A sharp eye for her SOI: The perception and misperception of female sociosexuality at zero acquaintance. Evolution and Human Behavior, 30, 124-130

West, S. G., Finch, J. F., \& Curran, P. J. (1995). Structural equation models with nonnormal variables: Problems and remedies. In R. H. Hoyle (Ed.), Structural equation modeling: Issues, concepts, and applications (pp. 56-75). Newbery Park, CA: Sage.

Witherspoon, R. G. (2016). Predictors of perceived stigmatization within consensually nonmonogamous relationships. ResearchGate. Retrieved from https://www.researchgate.net/publication/318431605_Predictors_of_Perceived_Stigmatiz ation_within_Consensually_Non-Monogamous_Relationships 
Vrangalova, Z., \& Ong, A. D. (2014). Who benefits from casual sex? The moderating role of sociosexuality. Social Psychological and Personality Science, 5, 883-891.

Zimmerman, K. J. (2012). Clients in sexually open relationships: Considerations for therapists. Journal of Feminist Family Therapy: An International Forum, 24, 272-289. 
Table 1.

Demographic Information for Monogamous, Polyamorous, Open, and Swinging Participants

\begin{tabular}{llllll}
\hline & Overall & Monogamous & Polyamorous & Open & Swinging \\
\hline Age - Mean (SD) & $32.07(9.45)$ & $32.35(9.99)$ & $32.02(8.39)$ & $31.49(8.68)$ & $30.63(6.69)$
\end{tabular}

Gender

$\begin{array}{llllll}\text { Male } & 58.28 \% & 54.14 \% & 66.13 \% & 65.00 \% & 73.08 \% \\ \text { Female } & 41.41 \% & 45.64 \% & 32.26 \% & 35.00 \% & 25.00 \% \\ \text { Other } & 0.31 \% & 0.22 \% & 1.61 \% & 0.00 \% & 1.92 \%\end{array}$

Race

$\begin{array}{lccccc}\text { White/Caucasian } & 65.83 \% & 71.81 \% & 43.55 \% & 48.75 \% & 67.31 \% \\ \text { Asian } & 18.56 \% & 13.65 \% & 29.03 \% & 33.75 \% & 25.00 \% \\ \text { Black } & 6.08 \% & 6.94 \% & 4.84 \% & 6.25 \% & 0.00 \% \\ \text { Hispanic } & 5.62 \% & 5.15 \% & 12.90 \% & 5.00 \% & 1.92 \% \\ \text { American Indian } & 1.72 \% & 0.89 \% & 4.84 \% & 2.50 \% & 3.85 \% \\ \text { Other } & 2.18 \% & 1.57 \% & 4.84 \% & 3.75 \% & 1.92 \%\end{array}$

Religious Affiliation

$\begin{array}{llllll}\text { Agnostic and Atheist } & 36.97 \% & 36.24 \% & 40.32 \% & 33.75 \% & 44.23 \%\end{array}$




$\begin{array}{llllll}\text { Buddhist and Hindu } & 10.76 \% & 6.94 \% & 17.74 \% & 22.50 \% & 17.31 \% \\ \text { Christian } & 43.53 \% & 48.55 \% & 29.03 \% & 35.00 \% & 30.77 \% \\ \text { Jewish } & 2.18 \% & 2.91 \% & 0.00 \% & 0.00 \% & 1.92 \% \\ \text { Muslim } & 1.25 \% & 0.89 \% & 0.00 \% & 2.50 \% & 3.85 \% \\ \text { Other } & 5.30 \% & 4.47 \% & 12.90 \% & 6.25 \% & 1.92 \%\end{array}$

Political Affiliation

$\begin{array}{lccccc}\text { Democrat } & 36.51 \% & 37.36 \% & 29.03 \% & 32.50 \% & 44.23 \% \\ \text { Republican } & 19.50 \% & 21.48 \% & 11.29 \% & 17.50 \% & 15.38 \% \\ \text { Independent/Unaffiliated } & 30.58 \% & 32.21 \% & 33.87 \% & 26.25 \% & 19.23 \% \\ \text { Other } & 13.42 \% & 8.94 \% & 25.80 \% & 23.75 \% & 21.16 \%\end{array}$

Sexual Orientation

$\begin{array}{llllll}\text { Heterosexual } & 84.56 \% & 89.26 \% & 67.74 \% & 77.50 \% & 75.00 \% \\ \text { Lesbian / Gay } & 3.43 \% & 2.91 \% & 4.84 \% & 5.00 \% & 3.85 \% \\ \text { Bisexual } & 10.30 \% & 6.26 \% & 24.19 \% & 16.25 \% & 19.23 \% \\ \text { Other } & 1.72 \% & 1.57 \% & 3.23 \% & 1.25 \% & 1.92 \%\end{array}$

Relationship Status

$\begin{array}{llllll}\text { Single } & 17.63 \% & 19.02 \% & 11.29 \% & 17.50 \% & 13.46 \%\end{array}$




$\begin{array}{llllll}\text { Dating } & 38.53 \% & 33.33 \% & 58.07 \% & 51.25 \% & 40.38 \% \\ \text { Engaged } & 5.62 \% & 6.71 \% & 1.61 \% & 3.75 \% & 3.85 \% \\ \text { Married } & 38.22 \% & 40.94 \% & 29.03 \% & 27.50 \% & 42.31 \%\end{array}$


Table 2.

Correlations Between Sexual Attitudes, Erotophobia-Erotophilia, and Sociosexuality Among Each Relationship Orientations

\begin{tabular}{|c|c|c|c|c|c|c|}
\hline $\begin{array}{l}\text { Target } \\
\text { Relationship } \\
\text { Orientation }\end{array}$ & 1. Permissiveness & 2. Instrumentality & 3. Communion & 4. Birth Control & $\begin{array}{l}\text { 5. Erotophobia- } \\
\text { Erotophilia }\end{array}$ & $\begin{array}{l}\text { 6. Sociosexual } \\
\text { Orientation }\end{array}$ \\
\hline \multicolumn{7}{|l|}{ Monogamous } \\
\hline 1 & - & & & & & \\
\hline 2. & $.35 * *$ & - & & & & \\
\hline 3. & .01 & $.21 * *$ & - & & & \\
\hline 4. & $.23 * *$ & $.19 * *$ & $.54 * *$ & - & & \\
\hline 5. & $.55^{*}$ & $.27 * *$ & .09 & $.32 * *$ & - & \\
\hline 6. & $.63 * *$ & $.18 * *$ & -.05 & .06 & $.50 * *$ & - \\
\hline \multicolumn{7}{|l|}{ Polyamorous } \\
\hline 1 & - & & & & & \\
\hline 2. & $.54 * *$ & - & & & & \\
\hline 3. & $.59 * *$ & $.41 * *$ & - & & & \\
\hline 4. & $.65 * *$ & .25 & $.54 * *$ & - & & \\
\hline 5. & $.44 * *$ & .01 & $.31 * *$ & $.41 * *$ & - & \\
\hline 6. & $.43 * *$ & .12 & .16 & .10 & $.43 * *$ & - \\
\hline \multicolumn{7}{|l|}{ Open } \\
\hline 1. & - & & & & & \\
\hline 2. & $.25 * *$ & - & & & & \\
\hline 3. & $.39 * *$ & $.39 * *$ & - & & & \\
\hline 4. & $.66^{* *}$ & $.25^{*}$ & $.58 * *$ & - & & \\
\hline 5. & $.54 * *$ & .03 & $.26^{*}$ & $.51 * *$ & - & \\
\hline 6. & $.43 * *$ & -.13 & -.09 & .18 & $.38 * *$ & - \\
\hline \multicolumn{7}{|l|}{ Swinger } \\
\hline 1 & - & & & & & \\
\hline 2. & $.70 * *$ & - & & & & \\
\hline
\end{tabular}




\begin{tabular}{|c|c|c|c|c|c|c|}
\hline 3. & $.69 * *$ & $.66^{* * *}$ & - & & & \\
\hline 6. & $.48 * *$ & .24 & .01 & $.29 *$ & $.56 * *$ & - \\
\hline
\end{tabular}

Note. $* *$ is significant at $p<.001 . *$ is significant at $p<.05$. 
Table 3.

Mean Scores on Dependent Measures and Mean Differences Between Monogamous and CNM Ratings

\begin{tabular}{cccccccccc}
\hline & \multicolumn{2}{c}{ Monogamous } & \multicolumn{2}{c}{ Polyamorous } & \multicolumn{3}{c}{ Open } & \multicolumn{2}{c}{ Swinging } \\
& $M$ & $S E$ & $M$ & $S E$ & $M$ & $S E$ & $M$ & $S E$ \\
& & & & & & & & \\
Sexual Attitudes Scale & & & & & & & & \\
Permissiveness & 2.88 & 0.05 & $3.82^{*}$ & 0.13 & $3.68^{*}$ & 0.12 & $4.10^{*}$ & 0.14 \\
Instrumentality & 3.02 & 0.04 & 3.31 & 0.12 & $3.46^{*}$ & 0.12 & $3.75^{*}$ & 0.13 \\
Communion & 3.74 & 0.48 & 3.84 & 0.13 & 3.64 & 0.12 & 3.99 & 0.13 \\
Birth Control & 4.08 & 0.06 & 4.21 & 0.14 & 3.89 & 0.13 & 4.30 & 0.05 \\
Sexual Opinion Survey & & & & & & & & \\
$\quad$ Erotophobia- & 77.37 & 1.04 & $88.67^{*}$ & 2.50 & 81.34 & 2.72 & $89.57^{*}$ & 3.21 \\
Erotophilia & & & & & & & & \\
Sociosexual Orientation & 3.58 & 0.08 & $4.96^{*}$ & 0.18 & $4.97^{*}$ & 0.19 & $5.85^{*}$ & 0.23 \\
Inventory & & & & & & & & \\
\hline
\end{tabular}

*indicates a significant difference $(p<.05)$ compared to monogamous partner evaluations. 
Table 4.

Mean Scores on Dependent Measures and Mean Differences Between Monogamous and CNM Ratings

\begin{tabular}{|c|c|c|c|c|c|c|c|c|c|c|c|c|c|c|c|c|c|c|}
\hline & \multicolumn{3}{|c|}{ SAS Permissiveness } & \multicolumn{3}{|c|}{ SAS Instrumentality } & \multicolumn{3}{|c|}{ SAS Communion } & \multicolumn{3}{|c|}{ SAS Birth Control } & \multicolumn{3}{|c|}{$\begin{array}{c}\text { Erotophobia- } \\
\text { Erotophilia }\end{array}$} & \multicolumn{3}{|c|}{ Sociosexual Orientation } \\
\hline & $t$ & $d$ & $d f$ & $t$ & $d$ & $d f$ & $t$ & $d$ & $d f$ & $t$ & $d$ & $d f$ & $t$ & $d$ & $d f$ & $t$ & $d$ & $d f$ \\
\hline $\begin{array}{l}\text { Mono- } \\
\text { Poly }\end{array}$ & $-6.65 * *$ & -0.91 & 499 & $-2.33^{*}$ & -0.32 & 499 & -0.69 & -0.09 & 499 & -0.85 & -0.12 & 499 & $-3.84 * *$ & -0.53 & 497 & $-6.44 * *$ & -0.88 & 501 \\
\hline $\begin{array}{l}\text { Mono- } \\
\text { Open }\end{array}$ & $-6.16 * *$ & -0.77 & 513 & $-3.96 * *$ & -0.50 & 513 & 0.81 & 0.10 & 513 & 1.29 & 0.16 & 513 & -1.43 & -0.18 & 510 & $-7.03 * *$ & -0.87 & 517 \\
\hline $\begin{array}{l}\text { Mono- } \\
\text { Swinger }\end{array}$ & $-7.90 * *$ & -1.17 & 489 & $-5.45^{* *}$ & -0.81 & 489 & -1.67 & -0.25 & 489 & -1.32 & -0.20 & 489 & $-3.76 * *$ & -0.56 & 487 & $-9.60 * *$ & -1.42 & 491 \\
\hline $\begin{array}{l}\text { Poly- } \\
\text { Open }\end{array}$ & 0.90 & 0.16 & 134 & -0.92 & -0.16 & 134 & 1.11 & 0.19 & 134 & 1.62 & 0.28 & 134 & 1.95 & 0.34 & 133 & -0.05 & -0.01 & 136 \\
\hline $\begin{array}{l}\text { Poly- } \\
\text { Swinger }\end{array}$ & -1.82 & -0.35 & 110 & $-2.27 *$ & -0.43 & 110 & -0.82 & 0.16 & 110 & -0.45 & -0.09 & 110 & -0.22 & -0.04 & 110 & $-3.15^{*}$ & -0.60 & 110 \\
\hline $\begin{array}{l}\text { Open- } \\
\text { Swinger }\end{array}$ & $-2.55^{*}$ & -0.46 & 124 & -1.71 & -0.31 & 124 & -1.91 & -0.35 & 124 & -2.12 & -0.38 & 124 & -1.95 & -0.36 & 123 & $-2.95^{*}$ & -.53 & 126 \\
\hline
\end{tabular}

*indicates a significant difference at $p<.05 ; * *$ indicates a significant difference at $p<.001$

Note. Sample consisted of 438 monogamous (mono) individuals, 61 polyamorous (poly), 77 open, and 51 swingers. The effect sizes presented are based on independent $t$-tests. The degrees of freedom vary in each analysis due to missing data points. 